\title{
Firing characteristics of nano-sized glass powders prepared by flame spray pyrolysis for electrode application
}

\author{
Jung Hyun KIM, Hye Young Ko0, You Na Ko, Jang Heui YI, Yun Chan KANG, ${ }^{\dagger}$ Hye Moon LEE* \\ and Jung Yeul YUN*
}

Department of Chemical Engineering, Konkuk University, 1 Hwayang-dong, Gwangjin-gu, Seoul 143-701, Korea
${ }^{*}$ Functional Materials Division, Korea Institute of Materials Science, 531 Changwonadaero, Changwon, Gyeongnam, 641-831, Korea

Bi-based glass powders with nanometer size as the additive of conducting paste were directly prepared by flame spray pyrolysis. The mean size of the powders increased from 37 to $52 \mathrm{~nm}$ as the concentration of spray solution was changed from 0.05 to $1 \mathrm{~mol} / \mathrm{L}$. The nano-sized glass powders prepared by flame spray pyrolysis had broad peaks at around $28^{\circ}$ in the XRD patterns. The glass transition temperature $\left(T_{\mathrm{g}}\right)$ of the nano-sized glass powders was $365^{\circ} \mathrm{C}$. The glass layer formed from the glass powders obtained from spray solution with low concentration of $0.05 \mathrm{~mol} / \mathrm{L}$ had clean surface at a firing temperature of $400^{\circ} \mathrm{C}$. On the other hand, the glass layers formed from the nano-sized glass powders obtained from spray solutions of 0.5 and $1 \mathrm{~mol} / \mathrm{L}$ had smooth surfaces at a firing temperature of $450^{\circ} \mathrm{C}$. Deviation of composition of nano-sized glass powders obtained from the spray solution with low concentration of $0.05 \mathrm{~mol} / \mathrm{L}$ occurred in the flame spray pyrolysis process. Therefore, crystallization of the glass powders occurred after firing.

(C2009 The Ceramic Society of Japan. All rights reserved.

Key-words : Flame spray pyrolysis, Glass powder, Nano powder, Electrode material

[Received July 15, 2009; Accepted October 15, 2009]

\section{Introduction}

Glass powders with nanometer size are required in many application fields such as flat panel displays and multilayer ceramic capacitors. ${ }^{1)-6)}$ Nano-sized glass powders are necessary to form the electrode layers with low thickness and high conductivity. Ink-jet technology which enables fine pattern processing of conducting electrodes by super-fine droplets also requires the nano-sized glass powders. ${ }^{4}$

Glass powders are mainly prepared by melting and quenching processes. Molten glasses at high temperatures in a platinum crucible are quenched to make glass flakes. The glass flakes were ground using various types of milling processes to obtain the glass powders. The glass powders formed from the conventional melting process have an irregular morphology and large size. Therefore, new preparation technologies for nano-sized glass powders are under development. Nano-sized glass powders with various compositions were prepared by thermal plasma synthesis. ${ }^{3)}$ In the thermal plasma processing of nano-sized glass powders, high energy densities of thermal plasmas are used to generate high-density vapor-phase precursors that are rapidly quenched to synthesize nano-sized glass powders. Submicronsized glass powders with spherical shape were directly prepared by spray pyrolysis. ${ }^{7,8)}$ In the spray pyrolysis, one glass particle was formed from one droplet. Therefore, nano-sized glass powders could not be prepared by spray pyrolysis operated at temperatures below $1500^{\circ} \mathrm{C}$.

Flame spray pyrolysis was widely applied to the preparation of nano-sized metal oxide and metal/metal oxide composite powders. ${ }^{9-14)}$ Flame spray pyrolysis was also applied to the preparation of nano-sized glass powders. Pb-based glass powders for

Corresponding author: Y. C. Kang; E-mail: yckang@ konkuk.ac.kr transparent dielectric layer were directly prepared by flame spray pyrolysis. ${ }^{1), 2)}$ Nano-sized glass powders were formed by chemical vapor deposition (CVD) process from the evaporated vapors composing the glass materials. Nano-sized glass powders had good characteristics as the transparent dielectric material. However, $\mathrm{Pb}$-free glass systems were not studied in the flame spray pyrolysis.

Bi-based glass materials are widely used as the additive materials for conducting electrodes. In this study, nano-sized Bi-based glass powders for additive material of conducting electrode were directly prepared by flame spray pyrolysis.

\section{Experiments}

Glass powders with a $42 \mathrm{wt} \% \mathrm{Bi}_{2} \mathrm{O}_{3}-23$ wt $\% \mathrm{~B}_{2} \mathrm{O}_{3}-19$ wt $\%$ $\mathrm{ZnO}-13 \mathrm{wt} \% \mathrm{BaO}-3 \mathrm{wt} \% \mathrm{SiO}_{2}$ composition were directly prepared by high-temperature flame spray pyrolysis. The system of flame spray pyrolysis has a droplet generator, flame nozzle, quartz reactor, powder collector, and blower. ${ }^{2)}$ A $1.7 \mathrm{MHz}$ ultrasonic spray generator with 6 resonators is used to generate droplets, which are carried into the high-temperature diffusion flame by oxygen, as the carrier gas. Droplets or powders evaporate, decompose, and melt inside the diffusion flame. Propane as the fuel and oxygen as the oxidizer create the diffusion flame. The flow rates of fuel, oxidizer and carrier gases were each 5, 40, and $10 \mathrm{~L} / \mathrm{min}$. The spray solutions were obtained by adding $\mathrm{Bi}_{2} \mathrm{O}_{3}$, $\mathrm{H}_{3} \mathrm{BO}_{3}, \mathrm{BaCO}_{3}, \mathrm{ZnO}$, tetraethyl orthosilicate (TEOS) and nitric acid to the mixed solvent of distilled water and ethyl alcohol. Ethyl alcohol was added to the spray solution to increase the temperature of diffusion flame. Volume ratio of ethyl alcohol to distilled water was 30:70.

The crystal structures of the prepared glass powders were investigated by X-ray diffraction (XRD, Rigaku Co., D/MAX$\mathrm{RB})$ with $\mathrm{Cu} \mathrm{K} \alpha$ radiation $(\lambda=1.5418 \AA)$. Measurement of the 
thermal properties of the prepared glass powders was performed on a thermo-analyzer (TG-DSC, Netzsch, STA409C) in the temperature range from 40 to $550^{\circ} \mathrm{C}$. The morphological characteristics of the prepared glass powders and fired glass layers were investigated by scanning electron microscopy (SEM, JEOL Ltd., JSM-6060) and high resolution transmission electron microscope (TEM, FEI, TECHNAI 300K). The transmittance of the glass layer was investigated by spectrophotometer within a visible light range (UV-Vis spectrophotometer, Shimadzu Co., UV2450).

\section{Results and discussion}

The morphologies of the glass powders prepared by flame spray pyrolysis from spray solutions with various concentrations

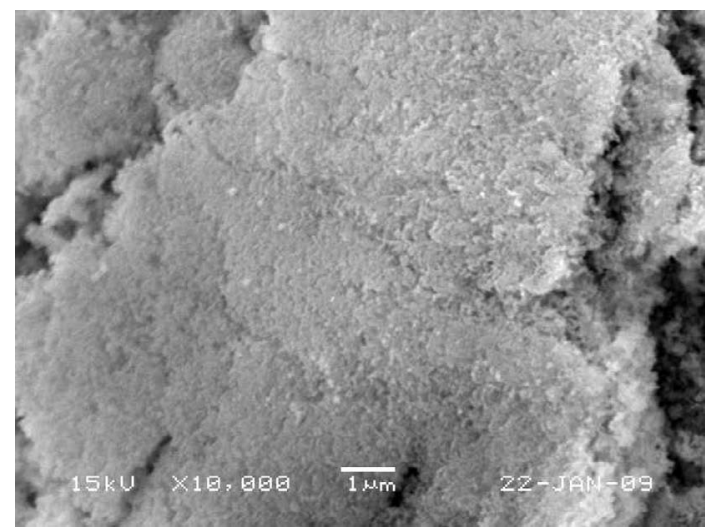

(a) $0.05 \mathrm{M}$

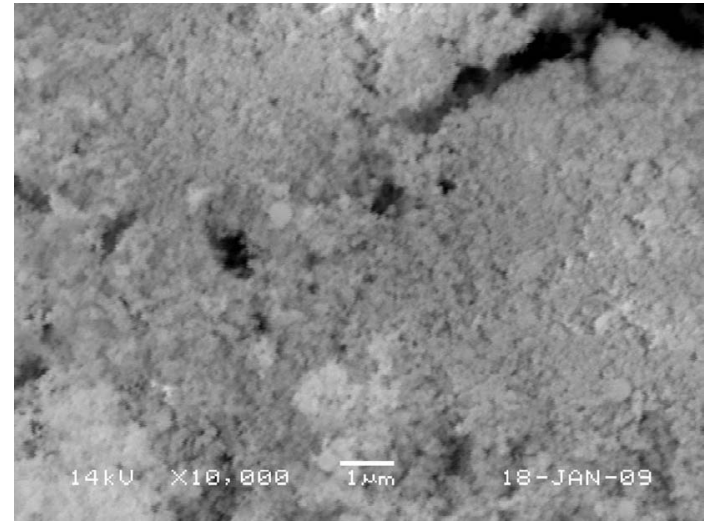

(b) $0.5 \mathrm{M}$

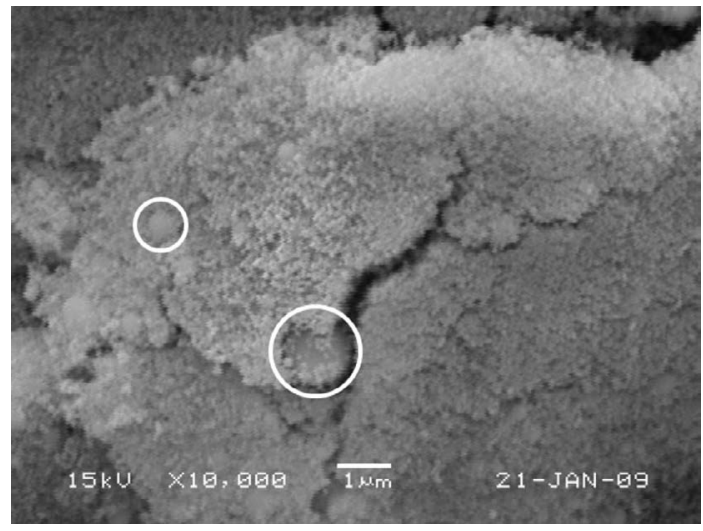

(c) $1 \mathrm{M}$

Fig. 1. SEM images of nano-sized glass powders prepared by flame spray pyrolysis. were shown in Fig. 1. Nano-sized glass powders were formed by flame spray pyrolysis irrespective of concentrations of spray solution. Evaporation of precursors composing the glass occurred inside the high temperature diffusion flame formed by propane fuel and oxygen oxidizer. In the flame spray pyrolysis, nano-sized glass powders were formed by chemical vapor deposition (CVD) process including nucleation and growth steps. However, a small number of submicron sized powders, which were indicated by circles, were observed from the powders prepared from spray solution with high concentration of $1 \mathrm{~mol} / \mathrm{L}$. In the flame spray pyrolysis, several micron-sized droplets are dried immediately after inlet to the diffusion flame to form the powders with submicron size. Decomposition or evaporation of the dried precursors depending on the type of the glass components occurred after drying to form the mixed oxide powders and vapors. Evaporation of the mixed oxide powders inside the high temperature diffusion flame occurred to form the vapors composing the glass components. However, complete evaporation of the glass components of the powders with large size did not occur. Therefore, nano-sized glass powders formed from spray solution with high concentration had a small number of submicron-sized glass powders.

The mean sizes and morphologies of the glass powders prepared by flame spray pyrolysis were investigated by TEM images as shown in Fig. 2. The powders were of nanometer size and completely spherical, irrespective of the concentration of the spray solution. Nano-sized glass powders were formed by gas phase reaction method and the powders had amorphous phases irrespective of concentration of spray solution as shown by electron diffraction patterns inside the TEM images. Therefore,

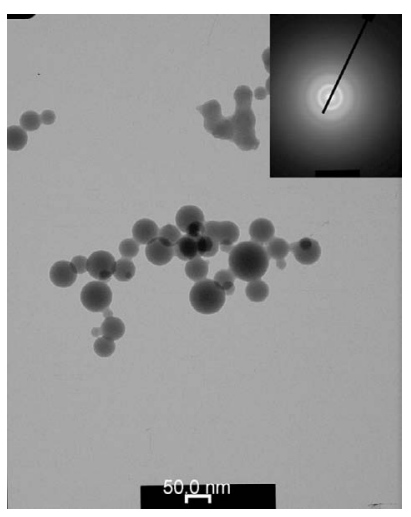

(a) $0.05 \mathrm{M}$

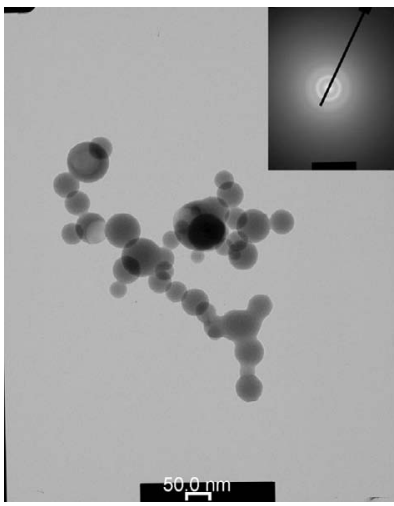

(b) $0.5 \mathrm{M}$

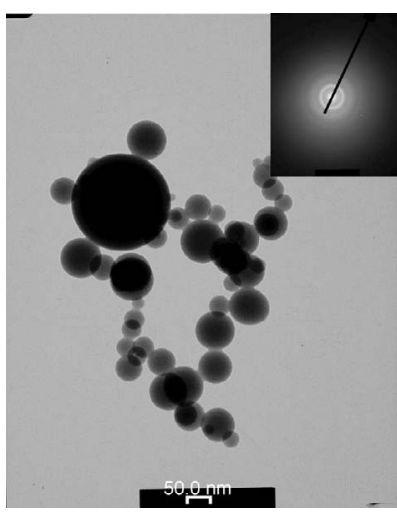

(c) $1 \mathrm{M}$
Fig. 2. TEM images and diffraction patterns of nano-sized glass powders prepared by flame spray pyrolysis. 
nano-sized glass powders formed by melting and quenching process had spherical shape to minimize the surface tension during the formation process. The mean size of the nano-sized glass powders were affected by concentration of spray solution. The mean sizes of the powders were determined from TEM images by counting more than 500 powders in each sample in order to minimize errors. The mean size increased from 37 to $52 \mathrm{~nm}$ as the concentration of spray solution was changed from 0.05 to $1 \mathrm{~mol} / \mathrm{L}$. The increase in the concentration of the spray solution caused an increase in the concentration of the vapors of the glass components inside the diffusion flame. The high concentration of vapors increased the number concentration of glass powders formed by the nucleation and growth mechanism. Therefore, the collision frequency between the glass powders and vapors increased. This high collision frequency between the powders and vapors increased the mean size of the nano-sized glass powders.

Figure 3 shows the XRD patterns of the nano-sized glass powders prepared by flame spray pyrolysis. The nano-sized glass powders prepared by flame spray pyrolysis had broad peaks at around $28^{\circ}$ in the XRD patterns, which represent the character of glass material. However, impurity peak of crystal structure with weak intensity was observed from the XRD pattern of the

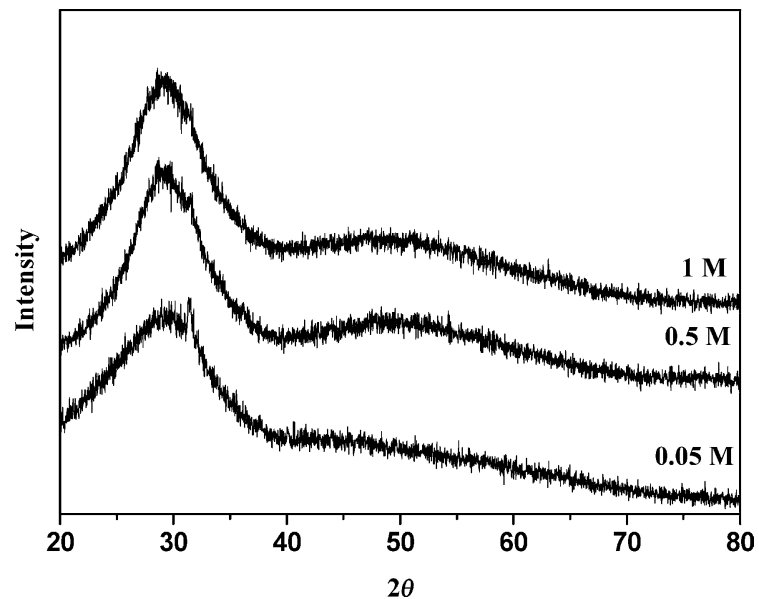

Fig. 3. XRD patterns of nano-sized glass powders prepared by flame spray pyrolysis.

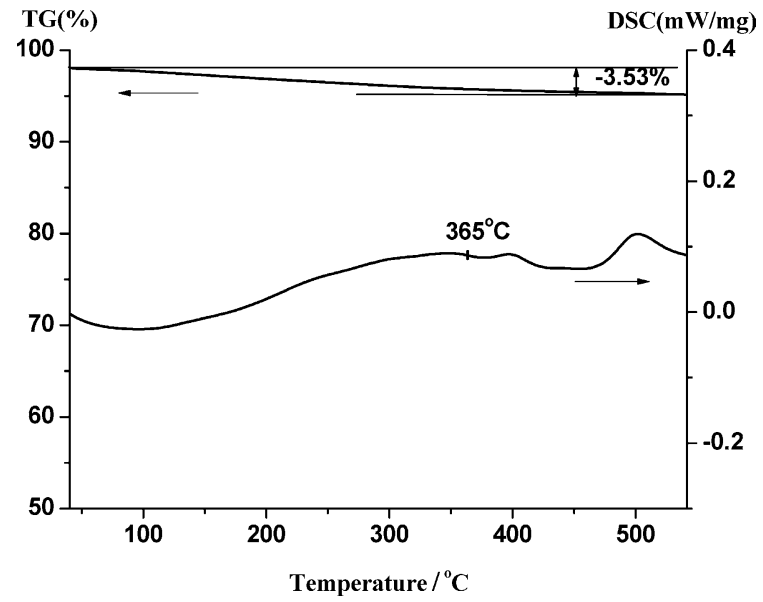

Fig. 4. TG and DSC curves of nano-sized glass powders prepared by flame spray pyrolysis. glass powders formed from spray solution with low concentration of $0.05 \mathrm{~mol} / \mathrm{L}$. The low concentration of spray solution generated the vapors of glass components with low concentration. The phase homogeneity of multicomponent oxide powders formed from the evaporated vapors decreased by decreasing the concentration of vapors. The formation of powders with glass phase is strongly affected by the composition of the powders. The slight deviation of the composition of the powders formed from the spray solution with low concentration caused the crystalline peak in the XRD pattern. Figure 4 shows the TG/DSC curves of the nano-sized glass powders prepared by flame spray pyrolysis. The concentration of spray solution was $0.5 \mathrm{~mol} / \mathrm{L}$. In the TG curve, the weight loss of the powders was $3.5 \mathrm{wt} \%$ of the powders at temperatures below $550^{\circ} \mathrm{C}$. The glass transition temperature $\left(T_{\mathrm{g}}\right)$ of the nano-sized glass powders was $365^{\circ} \mathrm{C}$. The

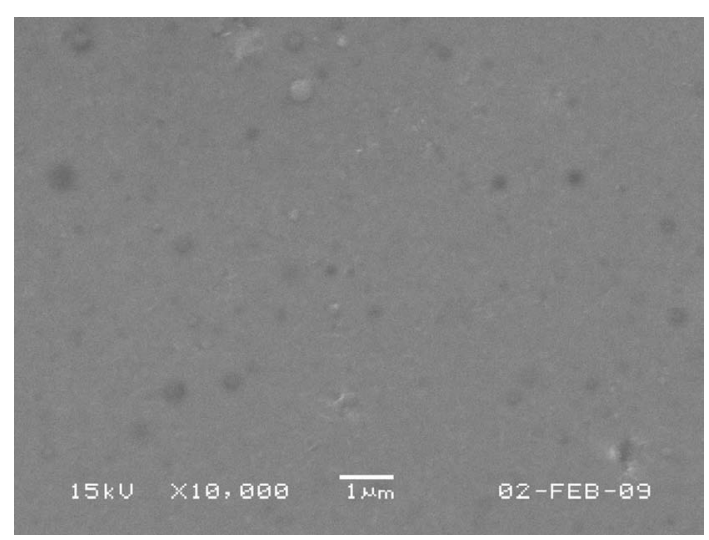

(a) $0.05 \mathrm{M}$

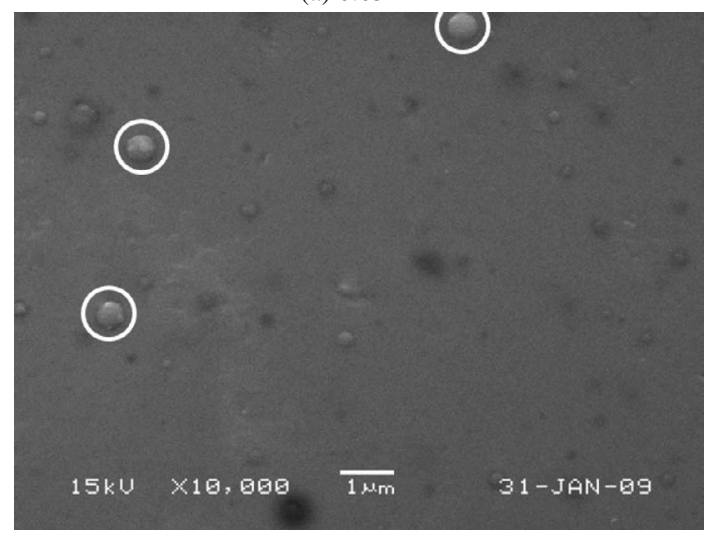

(b) $0.5 \mathrm{M}$

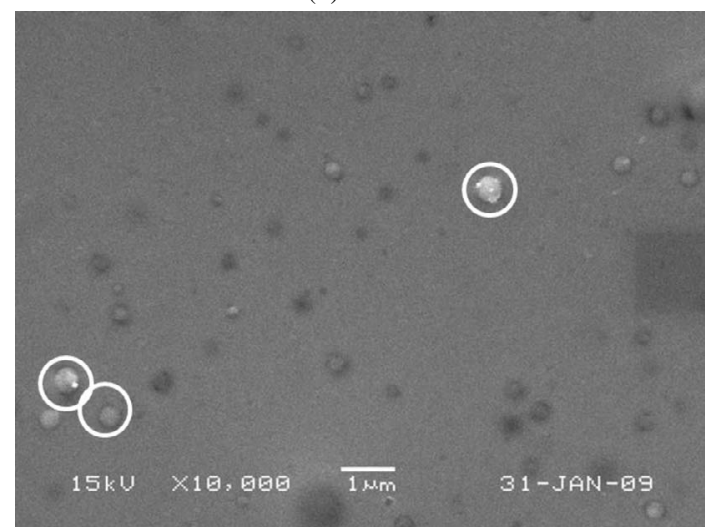

(c) $1 \mathrm{M}$

Fig. 5. SEM images of surfaces of the glass layers fired at $400^{\circ} \mathrm{C}$ 
weak peaks indicating the crystallization temperatures were observed at temperatures of 397 and $502^{\circ} \mathrm{C}$.

Melting characteristics of glass powders as additive of conducting paste are important. The melting characteristics of the nano-sized glass powders at various firing temperatures were investigated. Nano-sized glass powders prepared by flame spray pyrolysis from spray solutions with various concentrations were mixed with an organic vehicle that consisted of ethyl cellulose, $\alpha$-terpineol, and butyl carbitol acetate (BCA). The glass paste was screen-printed onto the soda-lime glass substrate. The printed glass substrate was dried at $120^{\circ} \mathrm{C}$ for $30 \mathrm{~min}$. The screen-printed glass substrate was fired by 2 steps, at first temperature of $400^{\circ} \mathrm{C}$ for $10 \mathrm{~min}$ at a heating rate of $5^{\circ} \mathrm{C} / \mathrm{min}$ and in the second temperatures between 400 and $500^{\circ} \mathrm{C}$ for $10 \mathrm{~min}$ at a heating rate of $5^{\circ} \mathrm{C} / \mathrm{min}$. Figures 5 and 6 show the SEM images
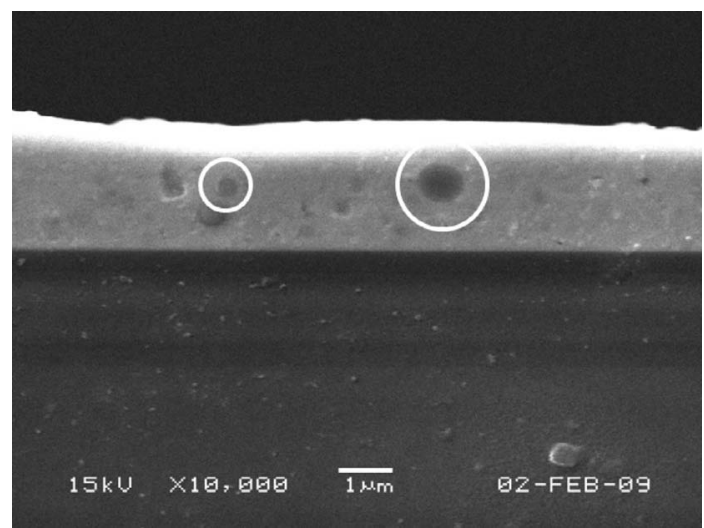

(a) $0.05 \mathrm{M}$
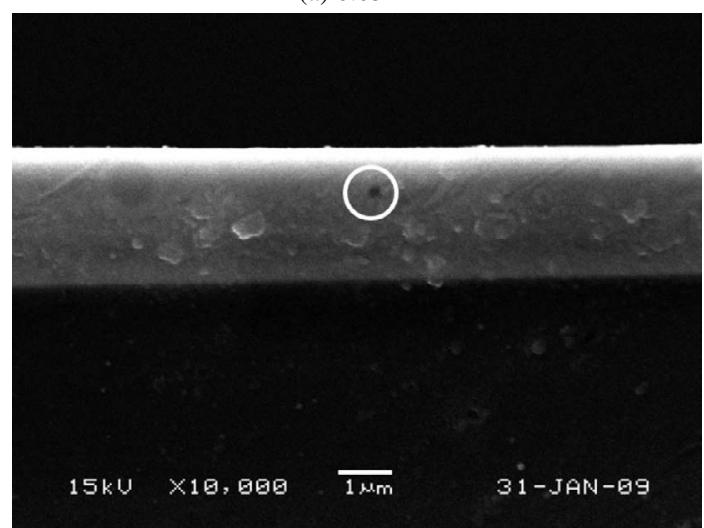

(b) $0.5 \mathrm{M}$

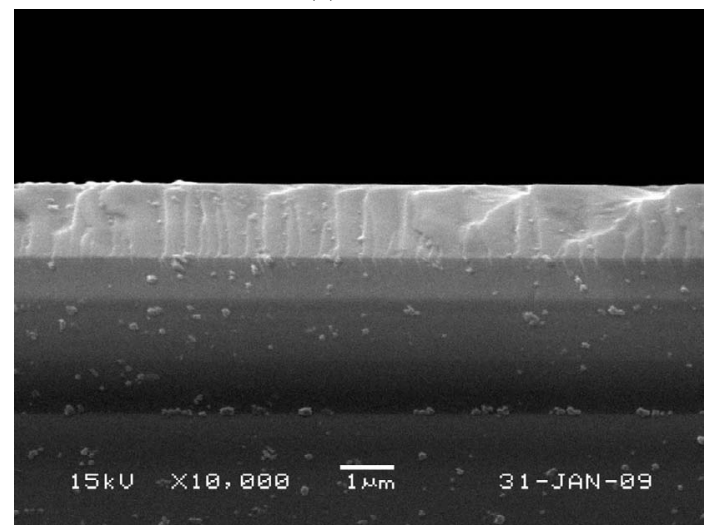

(c) $1 \mathrm{M}$

Fig. 6. SEM images of cross sections of the glass layers fired at $400^{\circ} \mathrm{C}$. of surfaces and cross sections of the glass layers fired at $400^{\circ} \mathrm{C}$. The glass layers formed from the glass powders had clean surfaces, in which melting of the glass powders occurred. However, the glass layers had some unmelted glass powders on the surfaces as shown by circles in Fig. 5. Nano-sized glass powders had lower softening temperature than that of the glass powders with submicron or micron sizes. Nano-sized glass powders melted at a firing temperature of $400^{\circ} \mathrm{C}$. On the other hand, a small number of glass powders involved in the nano-sized glass powders did not melt at a low firing temperature of $400^{\circ} \mathrm{C}$. The glass layers formed from the glass powders obtained from spray solutions with various concentrations had some voids inside the layers indicated by circles in Fig. 6 at a firing temperature of $400^{\circ} \mathrm{C}$.

Figures 7 and 8 show the SEM images of surfaces and cross

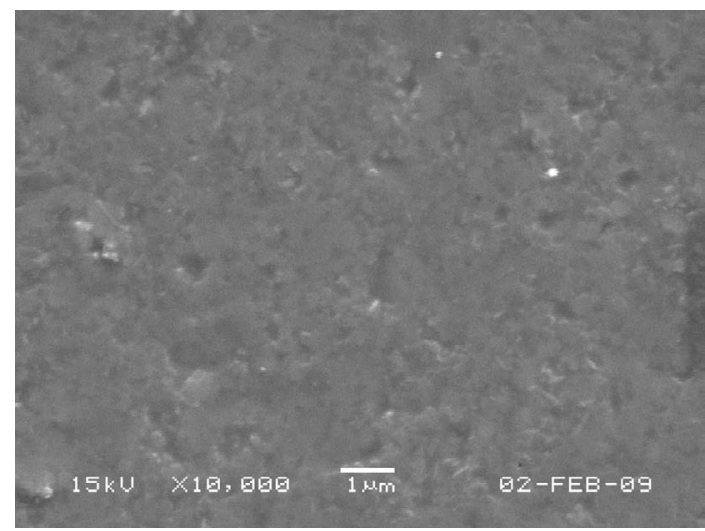

(a) $0.05 \mathrm{M}$

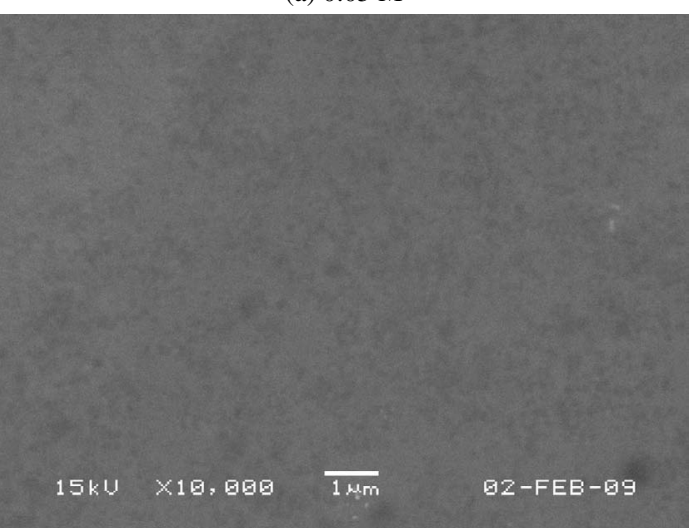

(b) $0.5 \mathrm{M}$

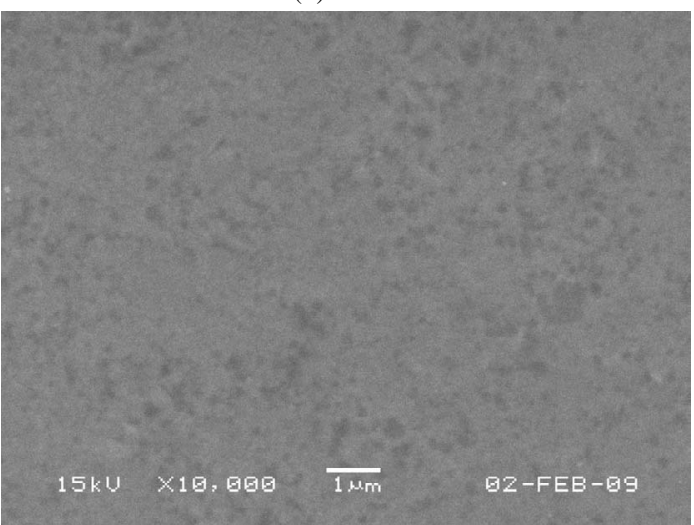

(c) $1 \mathrm{M}$

Fig. 7. SEM images of surfaces of the glass layers fired at $450^{\circ} \mathrm{C}$ 


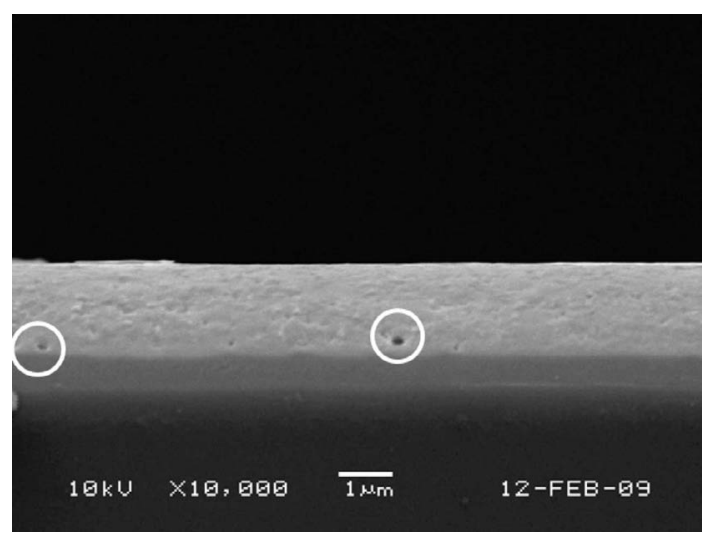

(a) $0.05 \mathrm{M}$

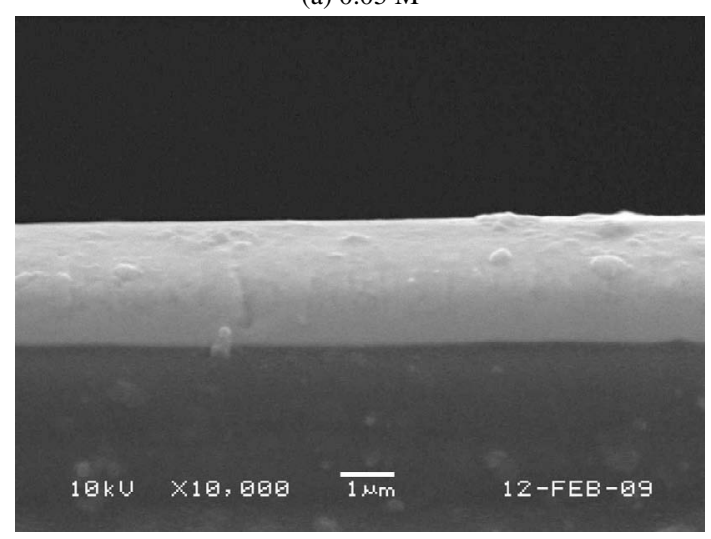

(b) $0.5 \mathrm{M}$
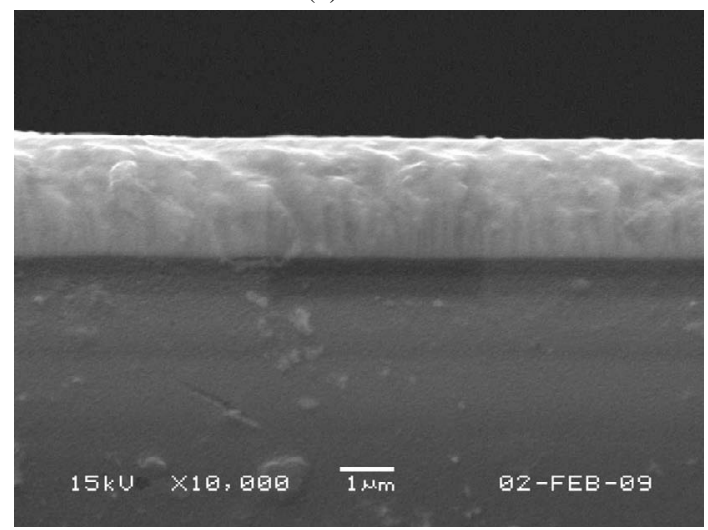

(c) $1 \mathrm{M}$

Fig. 8. SEM images of cross sections of the glass layers fired at $450^{\circ} \mathrm{C}$.

sections of the glass layers fired at $450^{\circ} \mathrm{C}$. The glass layers fired at $450^{\circ} \mathrm{C}$ had clean surfaces, in which unmelted glass powders were not observed. Submicron-sized glass powders involved in the glass samples obtained from spray solutions with high concentrations melted at a firing temperature of $450^{\circ} \mathrm{C}$. The glass layers formed from the nano-sized glass powders obtained from spray solutions of 0.5 and $1 \mathrm{~mol} / \mathrm{L}$ had smooth surfaces. On the other hand, glass layer formed from the nano-sized glass powders obtained from spray solution of $0.05 \mathrm{~mol} / \mathrm{L}$ had rough surface. Crystallization of glass increased the roughness of the glass layer. The glass layer formed from the glass powders obtained from spray solution of $0.05 \mathrm{~mol} / \mathrm{L}$ had some voids inside the layer indicated by circles in Fig. 8(a). On the other hand, the glass layers formed from the glass powders obtained from spray solutions of 0.5 and $1 \mathrm{~mol} / \mathrm{L}$ had dense inner structures without

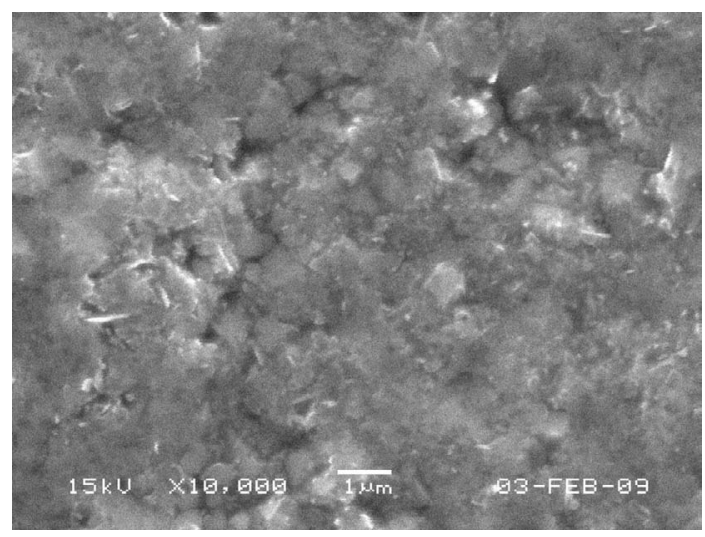

(a) $0.05 \mathrm{M}$

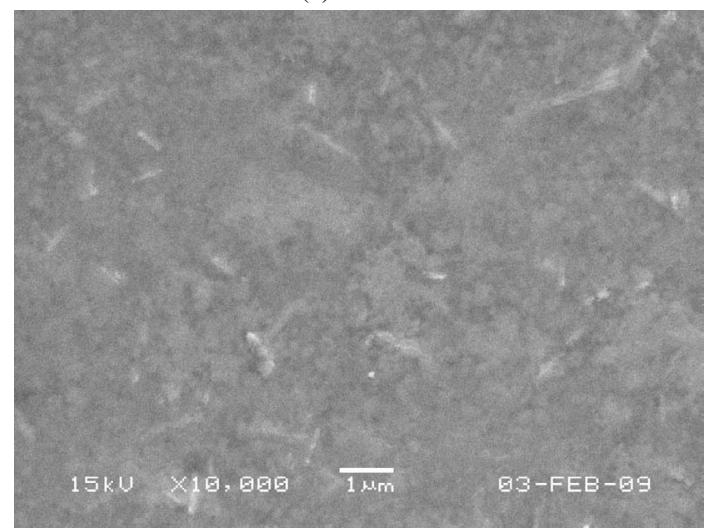

(b) $0.5 \mathrm{M}$

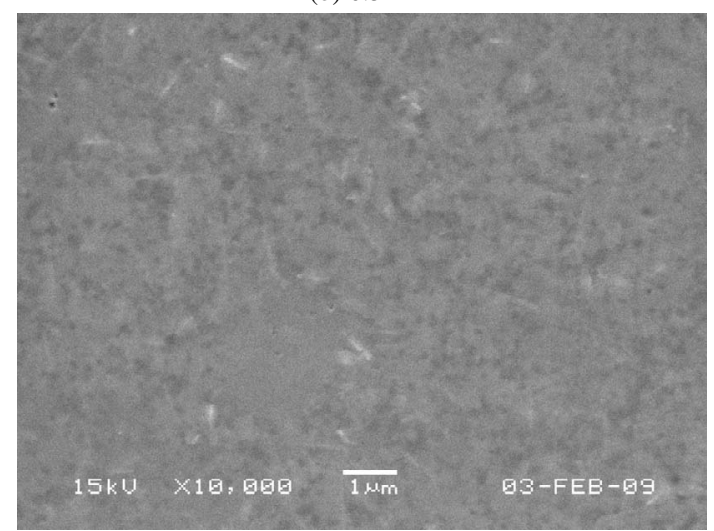

(c) $1 \mathrm{M}$

Fig. 9. SEM images of surfaces of the glass layers fired at $500^{\circ} \mathrm{C}$.

voids.

Figure 9 shows the SEM images of surfaces of the glass layers fired at $500^{\circ} \mathrm{C}$. The roughness of the glass layers increased with increases of the firing temperature. Crystal growth at a high firing temperature increased the roughness of the glass layers. In Figs. 7 and 9, observable crystallization phenomena of glass layers formed from the nano-sized glass powders obtained from the spray solution with low concentration of $0.05 \mathrm{~mol} / \mathrm{L}$ occurred. Deviation of composition of nano-sized glass powders obtained from the spray solution with low concentration of $0.05 \mathrm{~mol} / \mathrm{L}$ occurred in the flame spray pyrolysis process. Therefore, crystallization of the glass powders occurred at high firing temperatures.

The crystallization characteristics of the glass layers formed from the nano-sized glass powders prepared by flame spray 


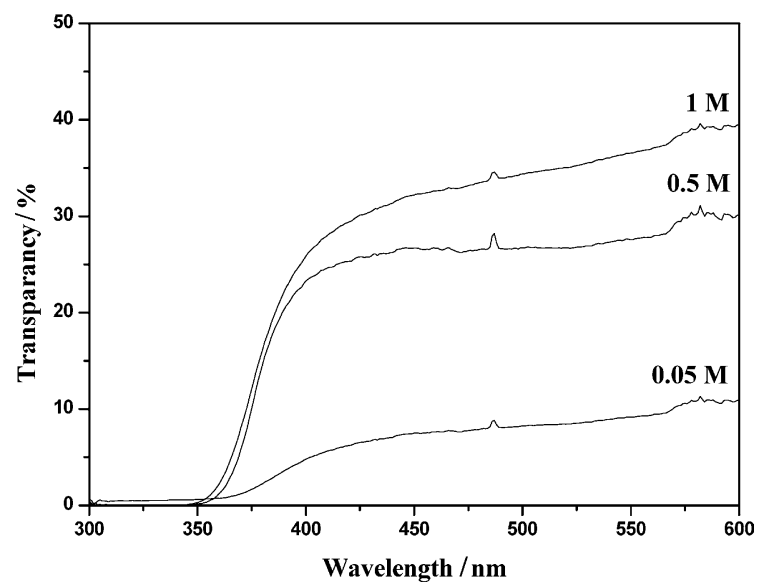

Fig. 10. Transparencies of the glass layers fired at $450^{\circ} \mathrm{C}$.

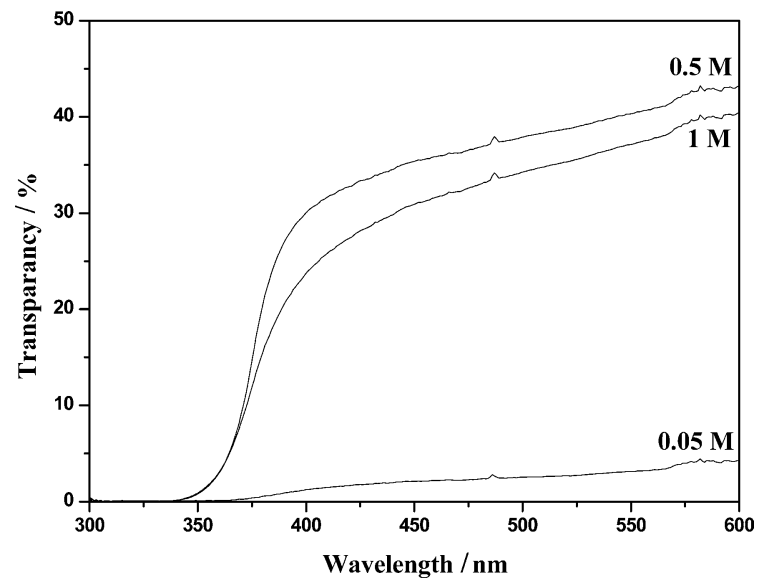

Fig. 11. Transparencies of the glass layers fired at $500^{\circ} \mathrm{C}$.

pyrolysis were investigated by transparencies of the layers. The transparencies of the glass layers fired at 450 and $500^{\circ} \mathrm{C}$ were shown in Figs. 10 and 11. The glass layers formed from the nano-sized glass powders obtained from the spray solutions of 0.5 and $1 \mathrm{~mol} / \mathrm{L}$ had similar transparencies near $30 \%$ in the visible light range. On the other hand, the glass layers formed from the nano-sized glass powders obtained from the spray solution of $0.05 \mathrm{~mol} / \mathrm{L}$ had poor transparencies below $10 \%$. The transparency of the glass layer formed from the nano-sized glass powders obtained from the spray solution of $0.05 \mathrm{~mol} / \mathrm{L}$ decreased when the firing temperature was increased from 450 to $500^{\circ} \mathrm{C}$. Crystallization of glass decreased the transparencies of the glass layers.

\section{Conclusion}

The effects of concentration of spray solution on the mean sizes, morphologies and firing characteristics of nano-sized glass powders prepared by flame spray pyrolysis were investigated. Nano-sized glass powders were formed by chemical vapor deposition process irrespective of concentration of spray solution. The mean sizes of the nano-sized glass powders decreased with decreasing concentration of the spray solution. However, deviation of composition of the glass powders formed from the spray solution with low concentration occurred. Therefore, the characteristics of the glass layers formed from the nano-sized glass powders were strongly affected by the mean sizes of the glass powders. Nano-sized glass powders formed from the spray solutions of high concentrations had good firing characteristics.

Acknowledgement This study was supported by a grant (M2009010025) from the Fundamental R\&D Program for Core Technology of Materials funded by the Ministry of Knowledge Economy (MKE), Republic of Korea.

\section{References}

1) J. S. Cho, S. K. Hong, D. S. Jung and Y. C. Kang, J. Ceram. Soc. Japan, 116, 334-340 (2008).

2) J. S. Cho, D. S. Jung, S. K. Hong and Y. C. Kang, J. Ceram. Soc. Japan, 116, 600-604 (2008).

3) J. H. Seo, D. U. Kim, J. S. Nam, S. H. Hong, S. B. Sohn and S. M. Song, J. Am. Ceram. Soc., 90, 1717-1722 (2007).

4) D. H. Jang, D. J. Kim, B. Y. Lee, S. S. Kim, M. S. Kang, D. K. Min and J. H. Moon, Adv. Funct. Mater., 18, 2862-2868 (2008).

5) H. Kishi, Y. Mizuno and H. Chazono, Jpn. J. Appl. Phys., 42, 1-15 (2003).

6) Y. Q. Wang, M. B. Tian, D. F. Zheng, M. Suehiro and S. I. Ogura, Br. Ceram. Trans. J., 101, 75-77 (2002).

7) S. K. Hong, D. S. Jung, J. S. Cho and Y. C. Kang, J. NonCryst. Solids, 354, 3012-3018 (2008).

8) H. Y. Koo, S. K. Hong, S. H. Ju, I. S. Seo and Y. C. Kang, J. Non-Cryst. Solids, 352, 3270-3274 (2006).

9) H. K. Kammler, L. Mädler and S. E. Pratsinis, Chem. Eng. Technol., 24[6], 583-596 (2001).

10) L. Mädler, H. K. Kammler, R. Mueller and S. E. Pratsinis, $J$. Aerosol Sci., 33[2], 369-389 (2002).

11) L. Mädler, W. J. Stark and S. E. Pratsinis, J. Mater. Res., 17[6], 1356-1362 (2002).

12) J. S. Cho and Y. C. Kang, J. Alloys Compd., 464[1-2], 282287 (2008).

13) H. Keskinen, J. M. Mäkelä, M. Vippola, M. Nurminen, J. Liimatainen, T. Lepistö and J. Keskinen, J. Mater. Res., 19[5], 1544-1550 (2004).

14) A. Purwanto, I. W. Lenggoro, H. K. Chang and K. Okuyama, J. Chem. Eng. Jpn., 39[1], 68-76 (2006). 